\section{Avian metabolism}

\section{Costs of migration in free-flying songbirds}

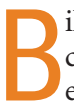
illions of songbirds migrate between continents twice each year, but the energy costs of this feat have never been measured for free-flying individuals. Here we follow New World Catharus thrushes during their nocturnal migratory flights ${ }^{1,2}$, recapturing individuals after journeys of up to $600 \mathrm{~km}$ and determining their energy expenditure by using doubly labelled water ${ }^{3,4}$. Although flight itself is costly, our results confirm the counterintuitive prediction that songbirds expend double the amount of energy during stopovers that they spend on flight over their entire migration ${ }^{5,6}$.

Quantifying the energy costs of migration should improve our understanding of songbird ecology ${ }^{7}$, but these costs have so far been estimated only from models ${ }^{8}$ and wind-tunnel studies ${ }^{6,8,9}$. To measure migration costs for free-flying Swainson's (Catharus ustulatus) and hermit (C. guttatus) thrushes, we injected 38 birds (each weighing about $30 \mathrm{~g}$; ref. 10) with $0.1 \mathrm{ml}$ doubly labelled water (containing ${ }^{2} \mathrm{H}$ and ${ }^{18} \mathrm{O}$ isotopes) in the morning and followed 12 throughout one nocturnal spring-migration flight for up to $600 \mathrm{~km}$ or $7.7 \mathrm{~h}$ (Fig. 1a) $)^{1,2}$; we followed six of these birds until they landed at a stopover habitat. Injected birds that did not make a migratory flight that night were treated as controls $(n=26)$. The next morning, we recaptured birds at 9:10 ( $\pm 1 \mathrm{~h} 40 \mathrm{~min}$ ) by mist-netting them and took a blood sample to quantify their energy expenditure ${ }^{4}$.

Our measurements indicate that both sustained natural flight and stopover are costly in cool weather (Fig. 1b, c). Migratory flight used $12.5 \mathrm{~kJ} \mathrm{~h}^{-1}$, determined as flying cost above resting metabolism, or $15.5 \mathrm{~kJ} \mathrm{~h}^{-1}$ (4.3 watts) total energy while flying, which agrees with predicted values $^{5,6,8}$; the cost of transport is 1.1 (calculated as a flight power of 4.3 watts divided by a flight speed of $13 \mathrm{~m} \mathrm{~s}^{-1}$ and a body weight of $0.3 \mathrm{~N}$ (equivalent to a body mass of $30 \mathrm{~g})$ ), which results in a mechanical cost of transport of about $0.25(1.1 \times 0.23$, where 0.23 is the energy-conversion efficiency).

These results for free-flying birds validate a generation of theoretical models $s^{5,8}$ and wind-tunnel studies ${ }^{9,11}$. Surprisingly, stopover thrushes that did not fly on cold nights incurred increased thermoregulation costs comparable to those of a 2.5 -h flight (Fig. 1b), illustrating the importance of climate during spring migration (Fig. 1c). Three of six migrating birds chose to stop over within $50 \mathrm{~m}$ of houses in urban or suburban areas.

We found that individual birds had roughly the same body weight and fat content in the mornings before and after their migratory flights ( $6 \%$ body-weight loss, no change in fat content), indicating that they probably regulate the duration of a migratory flight according to their body weight and fat stores ${ }^{6}$.

We can now estimate the energy expenditure of spring migration in a songbird ${ }^{11}$. Catharus thrushes can travel from Panama to Canada in 42 days $^{10}$. Only 18 of 42 days include nocturnal flights, which are $265 \mathrm{~km}$ on average ( $4.6 \mathrm{~h}$ in flight; Fig. 1b). The average cost for migration days is $130 \mathrm{~kJ}$, of which $71.3 \mathrm{~kJ}$ is spent on flight alone; the remaining 24 days are stopovers where an average of $88 \mathrm{~kJ} \mathrm{~d}^{-1}$ is expended, assuming an ambient temperature similar to that in central Illinois. For a $4,800-\mathrm{km}$ migration, about $4,450 \mathrm{~kJ}$ is spent - an overall cost of some $0.93 \mathrm{~kJ} \mathrm{~km}^{-1}$.

Our measurements indicate that actual flight represents only $29 \%$ of total energy expenditure during the entire migration, confirming the predicted 1:2 ratio of energy costs during flight versus stopover ${ }^{6}$. These calculations do not take into account adverse weather conditions, which could strongly affect the energy balance, or the wide variation in stopover costs for different habitats ${ }^{7}$. Days that include migratory flight $\left(130 \mathrm{~kJ} \mathrm{~d}^{-1}\right)$ are significantly less expensive than days spent feeding large chicks, for example ${ }^{12}$.

We suggest that the timing of migration in relation to climate, particularly the ambient temperature, is important for birds that use twice as much energy during stopover as during migratory flight. Springtime reverse migration ${ }^{13}$ can now be better understood as an energy-saving strategy to minimize thermoregulation costs.

Martin Wikelski ${ }^{\dagger}$, Elisa M. Tarlow $\dagger$, Arlo Raim $\neq$, Robert H. Diehl $\dagger$, Ronald P. Larkin $\ddagger$, G. Henk Visser\$ ${ }^{*}$ Department of Ecology and Evolutionary Biology, Princeton University, New Jersey 08544, USA e-mail:wikelski@princeton.edu

$\dagger$ Department of Animal Biology, University of Illinois at Urbana-Champaign, Illinois 61801, USA ¥Illinois Natural History Survey, Champaign, Illinois, USA

$\$$ Centre for Isotope Research, Groningen University, 9747 AG Groningen, The Netherlands, and

\section{IZoological Laboratory, Haren, The Netherlands}

1. Cochran, W. in Animal Orientation and Navigation (eds Galler, S. R., Schmidt-Koenig, K., Jacobs, G. J. \& Belleville, R. E.) 39-59 (NASA, Washington DC, 1972).

2. Cochran, W. Anim. Behav. 35, 927-929 (1987).

3. Nagy, K. A. Am. J. Physiol. 238, 454-473 (1980).

4. Speakman, J. R. Doubly Labeled Water: Theory and Practice (Chapman and Hall, London, 1997).

5. Hedenström, A. \& Alerstam, T. J. Theor. Biol. 189, 227-234 (1997).

6. Alerstam, T. \& Hedenström, A. J. Avian Biol. 29, 343-369 (1998).

7. Faaborg, J., Brittingham, M., Donovan, T. \& Blake, J. in Ecology and Management of Neotropical Migratory Birds: A Synthesis and Review of Critical Issues (eds Martin, T. E. \& Finch, D. M.) 357-380 (Oxford Univ. Press, New York, 1995).

8. Pennycuick. C. J. J. Theor. Biol. 191, 47-61 (1998).

9. Klaassen, M. J. Exp. Biol. 199, 57-64 (1996).

10. Graber, R. R., Graber, J. W. \& Kirk, E. L. Biol. Notes No. 75 (Illinois Natural History Survey, Champaign, Illinois, 1971). 11. Masman, D. \& Klaasen, M. Auk 104, 603-616 (1987). 12. Bennett, P. \& Harvey, P. H. J. Zool. 213, 327-363 (1987). 13. Richardson, W. J. Oikos 30, 224-272 (1978). Competing financial interests: declared none.

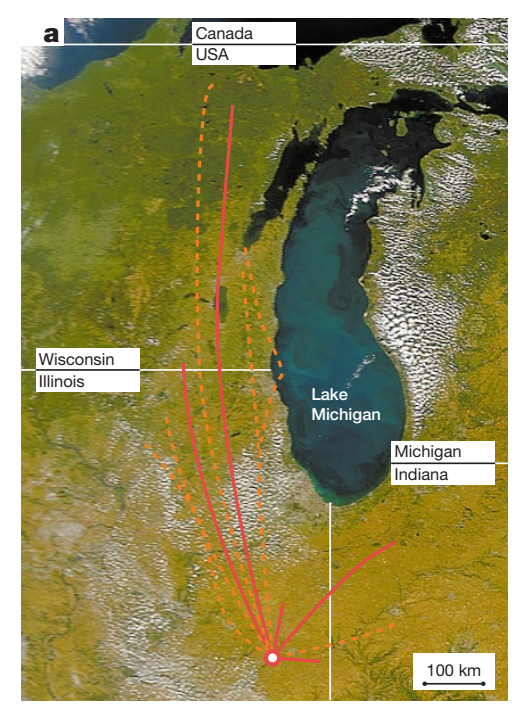

b
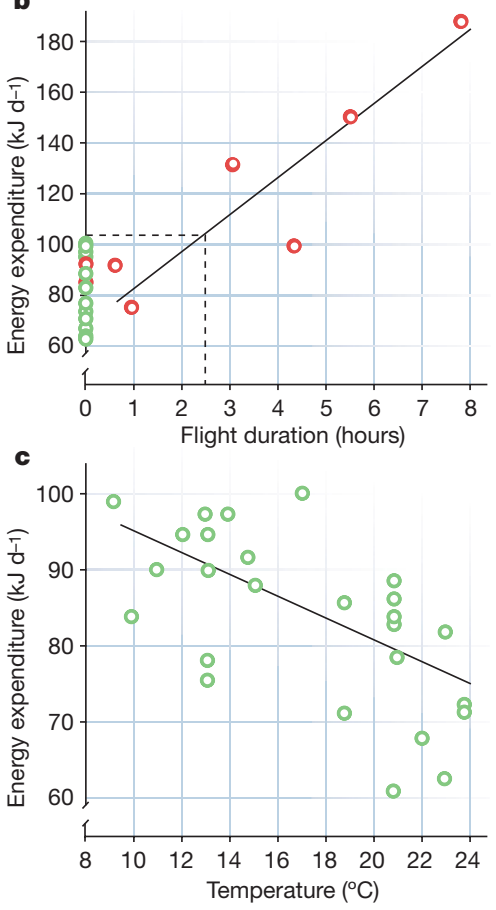

Figure 1 Migration routes and energetics of Swainson's and hermit thrushes during April and May in 1999 and 2000 (refs 1, 2, 10). We pooled data for final analysis because all traits were statistically indistinguishable between species ${ }^{10}$. a, Tracks for 12 individuals starting from Urbana, Illinois: full lines, recaptured birds; dashed lines, lost birds. Ends of lines indicate stopover sites. b, Daily energy expenditure (DEE) of migrating (red symbols) and stopover (green symbols) birds; for migrating birds, this is described as a linear regression: DEE $(\mathrm{kJ})=70( \pm 9)+12.5$ $( \pm 2.1) \times$ flight duration in hours; $r^{2}=0.89, P=0.004$ (standard deviations are given in parentheses) (ref. 11). Dashed line, average flight duration below which energy expenditure is indistinguishable from stopover controls (2.5 h). c, Variability in energy expenditure of birds during stopover is explained by differences in average daily ambient temperature (DEE $(k J)=109.6$ $( \pm 6.5)-1.52 \quad( \pm 0.37) \times$ ambient temperature; $r^{2}=0.4$, $n=26, P<0.001)$. We calibrated measurements using doubly labelled water with five birds held in a respirometer for $24 \mathrm{~h}$ (accuracy of $\pm 4 \%$ according to equation 7.17 of ref. 4). 